\title{
HUBUNGAN LETAK LESI HEMISFER SEREBRAL DAN DERAJAT KLINIS KECEMASAN PADA PENDERITA STROKE ISKEMIK
}

\author{
RELATIONSHIP BETWEEN LOCATION OF CEREBRAL HEMISPHERE \\ LESION AND CLINICAL DEGREES OF ANXIETY IN ISCHEMIC STROKE \\ PATIENTS
}

Yelly Marliana Patu, * Audry Devisanty Wuysang, * Nadra Maricar*

\section{ABSTRACT}

Introduction: Stroke is the leading cause of disability and the third cause of death in the world. The lesion in the right hemisphere is most often associated with anxiety.

Aim: Knowing the relationship between the location of the lesion and the degree of anxiety in patients with acute ischemic post-stroke.

Method: Cross-sectional study of 40 ischemic post-stroke patients at Wahidin Sudirohusodo Hospital and networking hospitals in January-April 2018. The degree of anxiety was measured by the Hamilton Anxiety Rating Scale (HARS). Chi-square and Mann-Whitney tests were used to analyze the relationship between variables with a p value $<0.05$ considered significant.

Result: There was a significant relationship between the location of the lesion in the hemisphere and the HARS score ( $p=0.01)$; and between the location of infarction lesions (cortical and subcortical) with the degree of anxiety in patients with ischemic stroke $(p=0.012)$.

Discussion: Moderate-severe anxiety levels occur higher in the lesions in the right hemisphere. The clinical instruments used cannot eliminate the element of subjectivity.

Keywords: Anxiety in stroke, ischemic stroke, left hemisphere, lesion location, right hemisphere

\section{ABSTRAK}

Pendahuluan: Stroke merupakan penyebab utama kecacatan dan kematian ketiga terbanyak di dunia. Lokasi lesi di hemisfer kanan merupakan lokasi lesi yang paling sering dikaitkan dengan timbulnya kecemasan.

Tujuan: Mengetahui hubungan antara lokasi lesi dan derajat kecemasan pada penderita pascastroke iskemik akut.

Metode: Desain potong lintang pada 40 sampel penderita pascastroke iskemik di RS Wahidin Sudirohusodo dan rumah sakit jejaring pada bulan Januari-April 2018. Derajat kecemasan diukur dengan Hamilton Anxiety Rating Scale (HARS). Uji Chi-square dan Mann-Whitney digunakan untuk menganalisis hubungan antar variabel dengan nilai $\mathrm{p}<0,05$ dianggap bermakna.

Hasil: Terdapat hubungan yang signifikan antara lokasi lesi di hemisfer dengan skor HARS ( $p=0,01)$; dan antara lokasi lesi infark (kortikal dan subkortikal) dengan derajat kecemasan pada penderita stroke iskemik $(p=0,012)$.

Diskusi: Derajat kecemasan sedang-berat lebih tinggi terjadi pada lesi di hemisfer kanan. Instrumen klinis yang digunakan tidak dapat menghilangkan unsur subjektifitas.

Kata kunci: Cemas pada stroke, hemisfer kanan, hemisfer kiri, letak lesi, stroke iskemik

*Bagian Neurologi FK Universitas Hasanuddin, Makassar. Korespondensi: yellymarlianapatu@gmail.com.

\section{PENDAHULUAN}

Stroke merupakan penyebab utama kecacatan dan penyebab ketiga kematian di dunia. ${ }^{1}$ Di Indonesia terdapat peningkatan kasus stroke, baik dalam hal kematian, angka kejadian, maupun penyebab kecacatan, termasuk di Sulawesi Selatan. ${ }^{2-3}$ Terdapat 67,6\% kasus stroke di Sulawesi Selatan dengan prevalensi tertinggi di Kabupaten Wajo (13,6\%) dan terendah di Kabupaten Pangkajene Kepulauan (2,9\%). ${ }^{4}$

Pasien pascaserangan stroke umumnya mengalami gangguan penyesuaian hingga satu bulan setelah kejadian yang dianggap "stressful", karena adanya disabilitas dalam kegiatan rutin sehari-hari. Adanya hendaya yang berdampak signifikan pada kehidupan sehari-hari dapat menimbulkan kecemasan (atau gejala yang mengindikasikan timbulnya gangguan kecemasan). ${ }^{5}$ Studi di Swedia melaporkan angka kejadian kecemasan pascastroke sebesar $6 \%$ di RS dan 3,5\% di komunitas. Di Norwegia didapatkan $36 \%$ pasien mengalami kecemasan dan 28\% pasien mengalami depresi pada 2-5 tahun pascastroke. ${ }^{6}$ Gangguan kecemasan juga dihubungkan dengan 
penurunan kualitas hidup terkait kesehatan (healthrelated quality of life/HRQoL) satu tahun setelah stroke. $^{7}$

Manifestasi gangguan bervariasi dan mencakup afek depresi, ansietas, atau gabungan keduanya, sesuai dengan penggolongan gangguan penyesuaian dalam Pedoman Penggolongan Diagnosis Gangguan Jiwa (PPDGJ)-III. Gangguan kecemasan ini sulit untuk dikendalikan dan berhubungan dengan gejala-gejala somatik, seperti ketegangan otot, iritabilitas, kesulitan tidur, dan kegelisahan, sehingga menyebabkan penderitaan dan gangguan yang bermakna dalam fungsi sosial dan pekerjaan. ${ }^{8-9}$

Timbulnya kecemasan dipengaruhi oleh beberapa faktor seperti ciri kepribadian, jenis kelamin, status sosial, penggunaan obat-obatan dan alkohol, jenis stroke, lokasi lesi, lamanya menderita stroke, beratnya kerusakan fungsi otak yang terjadi, lamanya proses pemulihan pascastroke. Penelitian yang dilakukan sebelumnya belum dapat memberikan data yang konsisten. ${ }^{9-10}$

Secara patofisiologi, kecemasan pascastroke disebabkan oleh ketidakseimbangan neurotransmiter. Neuron gamma-aminobutyric acid (GABA) dari sistem limbik, terutama pada area hipokampus, memodulasi terjadinya gangguan cemas menyeluruh, ketakutan, dan kewaspadaan. Konsentrasi GABA yang sangat tinggi pada reseptornya dengan pengikatan oleh struktur benzodiazepin dapat menurunkan status kewaspadaan yang tinggi. Peranan GABA pada gangguan ini berbeda dengan norepinefrin. Norepinefrin bersifat merangsang timbulnya kecemasan, sedangkan GABA bersifat menghambat terjadinya kecemasan ini. ${ }^{11}$

Gangguan neuropsikiatri, seperti skizofrenia, gangguan mood, kecemasan, depresi, dan lain-lain dilaporkan terkait dengan lesi di hemisfer kanan. ${ }^{12}$ Gangguan patologis tersebut dapat berupa tumor, stroke, atau adanya malformasi arteriovenosa di regio temporal atau frontotemporal kanan. ${ }^{13-15}$

Namun penelitian juga mendapatkan ketidaksimetrisan anatomi dan biokimiawi antara hemisfer kanan dan hemisfer kiri. Hal ini menyebabkan perbedaan angka kejadian gangguan neuropsikiatri terkait dengan lesi di hemisfer kanan atau di hemisfer kiri, atau antara lesi di kortikal dan subkortikal. ${ }^{16-18}$

Lokasi lesi di hemisfer kanan merupakan lokasi lesi yang paling sering dikaitkan dengan timbulnya kecemasan. Sejauh ini belum pernah dilakukan perbandingan derajat kecemasan dengan lesi stroke iskemik di hemisfer kiri. Informasi yang didapatkan penting dalam perencanaan perawatan penderita stroke serta komplikasi dan prognosisnya.

Instrumen penilaian kecemasan yang sering digunakan adalah kuesioner Hamilton Anxiety Rating Scale (HARS) dengan sensitivitas 68,8\% dan spesifisitas $87,5 \%$ dalam mendiagnosis kecemasan. ${ }^{22}$

\section{TUJUAN}

Mengetahui hubungan antara lokasi lesi infark antara hemisfer kanan dan kiri dengan derajat gangguan kecemasan pada penderita stroke iskemik.

\section{METODE}

Penelitian ini dilakukan di RS Wahidin Sudirohusodo dan jejaringnya pada bulan JanuariApril 2018, berupa penelitian survei analitik dengan rancangan potong lintang.

Subjek adalah penderita stroke iskemik yang kemudian dibagi dalam dua kelompok berdasarkan hasil CT scan kepala (kelompok hemisfer kanan dan hemisfer kiri). Computed tomography scan kepala dilakukan dalam waktu 14 hari hingga 1 bulan pascastroke iskemik. Subjek akan dieksklusi dari penelitian jika lesi tidak terlihat pada CT scan kepala.

Hasil penilaian kuesioner HARS digolongkan menjadi: tidak cemas (skor 0), ringan (skor 1-17), ringan-sedang (skor 18-24), sedang-berat (skor 25-30), dan berat (skor 31-56). Pemeriksaan ini dilakukan 14 hari pascaawitan stroke sesuai dengan ketentuan DSM IV dan PPDGJ III mengenai kecemasan pascastroke minimal dua minggu setelah serangan stroke.

Penilaian HARS dilakukan pada pasien yang memiliki GCS 15 dan tidak memiliki kriteria eksklusi. Kriteria eksklusi meliputi pasien yang tidak kooperatif atau tidak mampu menjawab pertanyaan, strok iskemik lebih dari 1 bulan setelah onset, afasia, lesi lain selain infark, infark akibat emboli, 
infark serebelum atau batang otak, lesi $>1$ di kedua hemisfer, riwayat ciri kepribadian kecemasan (menghindar) sebelumnya, riwayat kecemasan atau gangguan jiwa yang lain sebelumnya, riwayat gangguan kecemasan dalam keluarga, riwayat konsumsi alkohol atau penggunaan obat-obatan yang memengaruhi neurotransmiter otak.

Analisis data dilakukan dengan program SPSS versi 17. Hubungan antar variabel diuji dengan uji Mann-Whitney.

\section{HASIL}

Selama periode penelitian ditemukan 40 subjek yang terdiri dari masing-masing 20 subjek pada kelompok lesi di hemisfer kanan dan kiri. Proporsi laki-laki hampir sama dengan perempuan, yaitu $57,5 \%$ dan $42,5 \%$ perempuan. Mayoritas pasien berusia lebih dari 45 tahun $(82,5 \%)$ dan mengalami kecemasan sedang-berat (60\%).

Subjek dengan lesi di hemisfer kanan (Tabel 1) lebih banyak mengalami kecemasan derajat sedang (85\%), sedangkan lesi kiri lebih banyak mengalami kecemasan derajat ringan (65\%).

Tabel 1. Perbandingan Derajat Kecemasan berdasarkan Lokasi Lesi $(n=40)$
Tabel 2. Perbandingan Skor HARS Berdasarkan Letak Lesi di Hemisfer $(n=40)$

\begin{tabular}{lccc}
\hline \multirow{2}{*}{ Skor HARS } & \multicolumn{2}{c}{ Letak Lesi Hemisfer } & \multirow{2}{*}{ p* } \\
\cline { 2 - 3 } & Kanan $(\mathbf{n}=\mathbf{2 0})$ & Kiri $(\mathbf{n}=\mathbf{2 0})$ & \\
\hline Rerata & 26,58 & 14,43 & \\
Simpang Baku & 5,886 & 7,155 & \\
Median & 23,50 & 15,00 & 0,01 \\
Minimum & 6 & 5 & \\
Maksimum & 30 & 29 & \\
\hline
\end{tabular}

*Uji Mann-Whitney.

dan alkohol, jenis stroke, lokasi lesi, lamanya menderita stroke, beratnya kerusakan fungsi otak yang terjadi, serta lamanya pemulihan pascastroke. ${ }^{10}$

Penderita stroke iskemik di hemisfer kanan pada penelitian ini lebih banyak mengalami kecemasan derajat ringan-sedang (50\%), sementara pada penderita stroke di hemisfer kiri lebih banyak yang mengalami kecemasan derajat ringan (65\%). Skor HARS rata-rata untuk lesi infark di hemisfer kanan lebih besar $(26,58)$ dibandingkan skor HARS rata-rata untuk lesi infark di hemisfer kiri $(14,43)$ secara bermakna $(p=0,01)$.

\begin{tabular}{lcccc}
\hline \multirow{2}{*}{ Lokasi Lesi Hemisfer } & \multicolumn{3}{c}{ Derajat Kecemasan } & \multirow{2}{*}{ Jumlah } \\
\cline { 2 - 4 } & Ringan & Ringan-Sedang & Sedang-Berat & \\
\hline Kanan & $3(15,0 \%)$ & $10(50,0 \%)$ & $7(35,0 \%)$ & 20 \\
Kiri & $13(65,0 \%)$ & $5(25,0 \%)$ & $2(10,0 \%)$ & 20 \\
Total & $16(40,0 \%)$ & $15(37,5 \%)$ & $9(22,5 \%)$ & 40 \\
\hline
\end{tabular}

*Uji Chi-square.

Rerata skor HARS penderita dengan lokasi lesi di hemisfer kanan $(26,58)$ signifikan $(p=0,01)$ lebih tinggi dibandingkan di hemisfer kiri $(14,43)$. Hal ini menunjukkan derajat kecemasan kelompok subjek dengan lesi di hemisfer kanan lebih berat dibandingkan lesi di hemisfer kiri (Tabel 2).

\section{PEMBAHASAN}

Mayoritas (82,5\%) subjek berumur $\geq 45$ dan mengalami kecemasan sedang-berat (60\%). Hal ini tidak jauh berbeda dengan penelitian sebelumnya, bahwa gangguan kecemasan terjadi pada $75 \%$ pasien stroke yang berusia lebih dari 45 tahun. ${ }^{19}$ Timbulnya kecemasan dipengaruhi oleh beberapa faktor, seperti jenis kelamin, status sosial, penggunaan obat-obatan
Hal itu menunjukkan adanya hubungan antara lokasi lesi dengan derajat kecemasan, yaitu derajat kecemasan untuk lokasi lesi di hemisfer kanan lebih berat dibandingkan derajat kecemasan yang terjadi pada penderita stroke iskemik dengan lokasi lesi di hemisfer kiri.

Pada gangguan kecemasan didapatkan peranan benzodiazepin dan neurotransmiter gamma-aminobutirat (GABA), yaitu terbentuknya kompleks GABA-benzodiazepin mengerahkan efek ansiolitik dengan cara meningkatkan aktivitas reseptor GABA tipe A. Stimulasi reseptor ini menghasilkan peningkatan ion klorida yang masuk 
ke dalam neuron (termasuk noradrenergik), yang menyebabkan hiperpolarisasi dan penurunan eksitabilitas. ${ }^{11}$

Peranan serotonin dalam gangguan kecemasan berdasarkan hasil pengamatan efektivitas obatobatan golongan serotonergik terhadap kecemasan, seperti buspiron atau buspar yang merupakan agonis reseptor serotonergik tipe $1 \mathrm{~A}\left(5-\mathrm{HT}_{1 \mathrm{~A}}\right)$. Diduga serotonin memengaruhi reseptor kompleks GABAbenzodiazepin, sehingga dapat berperan sebagai antiansietas. Kemungkinan lain adalah interaksi antara serotonin dan norepinefrin yang juga berperan sebagai antiansietas. ${ }^{20}$

Terdapat dua teori dasar mengenai peranan hemisfer kanan dalam memediasi kelainan emosi dan perilaku, yaitu gangguan emosi dan perilaku akibat lesi pada salah satu sisi menggambarkan adanya gangguan pada keseimbangan interhemisferik. Hal ini juga disebabkan karena adanya disfungsi pada hemisfer ipsilateral. Akibat adanya perbedaan konsentrasi neurotransmiter antara kedua hemisfer, maka lateralisasi lesi menjadi penyebab timbulnya perbedaan sindrom spesifik hemisfer. ${ }^{12}$

Subjek tidak dilakukan penilaian berat ringannya hendaya motorik oleh karena penelitian ini dilakukan setelah dua minggu awitan stroke, berarti kecemasan yang terjadi adalah akibat gangguan organik otak. Setelah timbulnya suatu serangan stroke, biasanya timbul gangguan penyesuaian 1 bulan setelah kejadian yang salah satunya disebabkan karena faktor hendaya motorik yang dianggap "stressful" dan menyebabkan disabilitas dalam kegiatan rutin sehari-hari. Manifestasinya dapat berupa afek depresi, kecemasan atau gabungan keduanya. Penelitian sebelumnya menemukan bahwa secara klinis, gangguan kecemasan dan depresi pada stroke fase akut sering dikaitkan dengan lesi yang terjadi, sedangkan gangguan kecemasan dan depresi sesudah fase akut cenderung akibat reaksi hendaya fisik. $^{21}$

Keterbatasan penelitian ini meliputi adanya keterlibatan subjektivitas peneliti dan sampel penelitian dalam kuesioner HARS. Perlu dilakukan penelitian lebih lanjut mengenai hubungan kecemasan dengan kadar GABA-serotonin, jumlah lesi intra serebral, dan lokasi lesi tertentu; serta hubungan kecemasan dengan hendaya motorik dan sensorik pada penderita stroke iskemik, dan luaran klinis penderita.

\section{KESIMPULAN DAN SARAN}

Terdapat hubungan antara derajat kecemasan pada penderita pascastroke iskemik akut dengan lokasi lesi infark (hemisfer kanan dan kiri), yaitu derajat kecemasan untuk lokasi lesi di hemisfer kanan lebih berat dibandingkan derajat kecemasan akibat lesi di hemisfer kiri.

Mengingat tingginya angka kecemasan pada penderita pascastroke sebaiknya dilakukan pemeriksaan derajat kecemasan menggunakan skor HARS secara rutin, sehingga dapat dilakukan penanganan cepat dan akurat serta tindakan pencegahan sebelumnya.

\section{DAFTAR PUSTAKA}

1. Brust J. Cerebral Infarction. Dalam: Rowland L, Pedley T, editor. Edisi ke-12. Merritt's Neurology. Philadelphia. Lippincot William \& Wilkins, 2010.

2. Pokdi Stroke Perhimpunan Dokter Spesialis Saraf Indonesia. Guideline Stroke 2011. Jakarta: Perhimpunan Dokter Spesialis Saraf Indonesia; 2011.

3. Badan Penelitian dan Pengembangan Kesehatan. Riset Kesehatan Dasar 2013. Jakarta: Kementrian Kesehatan Republik Indonesia; 2013. h. 91-4.

4. Syahrir. Profil Kesehatan Provinsi Sulawesi Selatan Tahun 2014. Makassar; 2015.

5. Campbell-Burton CA, Murray J, Holmes J, Astin F, Greenwood D, Knapp P. Frequency ofanxiety after stroke: A systematic review and meta-analysis of observational studies. Int JStroke. 2013;8(7):545-59.

6. Bergersen H, Froslie KF, Stibrant-Sunnerhagen K, Schanke AK. Anxiety, depression, andpsychological well-being 2 to 5 years poststroke. J Stroke Cerebrovasc Dis. 2010;19(5):364-9.

7. Donnellan C, Hickey A, Hevey D, O’Neill D. Effect of mood symptoms on recovery oneyear after stroke. Int J Geriatr Psychiatry. 2010;25(12):1288-95.

8. Kaplan H. Mood disorder. Dalam: Sadock B, Sadock V, Ruiz P, editor. Kaplan and Sadock's synopsis of psychiatry behavioural science/clinical psychiatry. Edisi ke-11. Philadelphia: Wolters Kluwer; 2015.

9. Maslim, R. Buku saku diagnosis gangguan jiwa, rujukan ringkas PPDGJ-III. Jakarta: Bagian Ilmu Kedokteran Jiwa Fakultas Kedokteran Universitas 
Katolik Atma Jaya; 2003. h. 70-5.

10. Merikangas KR, Pine D. Genetic and other vulnerability factors for anxiety and stress disorders. Neuropsychopharmacology: The Fifth Genereration of Progress. 2002;61:868-78.

11. Shiloh R, Stryjer R, Weizman A, Nutt DJ. Atlas of psychiatric pharmacotherapy. Edisi ke-2. London: Taylor and Francis; 2006. h. 87-96.

12. Cummings JL. Neuropsychiatric manifestations of right hemisphere lesions. Brain Lang. 1997;57:22-37.

13. Capwell RR, Carter R. Organic anxiety syndrome secondary to metastatic brain tumor. Psychosomatics. 1991;32:231-3.

14. Drubach DA, Kelly MP. Panic disorder associated with a right paralimbic lesion. Neuropsychiatry Neuropsychol Behav Neurol. 1989;2:282-9.

15. George MS, McLeod-Bryant S, Lydiard RB, Kurent JE, Zealberg J. Panic attacks and agoraphobia associated with a giant right cerebral arteriovenous malformation. Neuropsychiatry Neuropsychol Behav Neurol. 1990;3:206-12.

16. Astrom M. Generalized anxiety disorder in stroke patients: a 3-year longitudinal study. Stroke. 1996;24:976-82.
17. Castillo CS, Schultz SK, Robinson RG. Clinical correlates of early-onset and late-onsetpoststroke generalized anxiety. Am J Psychiatry. 1995;152(8): 1174-81.

18. Starkstein SE, Robinson RG, Price TR. Comparison of cortical and subcortical lesions in the production of poststroke mood disorders. Brain. 1987;110:104559.

19. Department of Health/Vascular Programme/Stroke. National stroke strategy. London: Department of Health; 2007.

20. Sadock B, Sadock V, Ruiz P. Kaplan and Sadock's comprehensive textbook of psychiatry. Edisi Ke-8. Wolters Kluwer; 2008.

21. Hartono P. Gangguan depresi pada penderita pasca stroke 8 minggu-3 bulan. Semarang: Departemen Psikiatri Fakultas Kedokteran Universitas Diponegoro; 2008

22. Wiglusz MS, Landowski J, Cubala WJ. Psychometric properties of the polish version of the Hamilton Anxiety Rating Scale in patients with epilepsy with and without comorbid anxiety disorder. Epilepsy Behav. 2019;94:9-13. 